\title{
BESEDA UREDNIKA
}

V zadnji lanski številki, 2018/28, smo se srečali z dvema (ob)letnicama, ki sta povezani z dvema velikima vojnama: letom 1918 in koncem Velike vojne (ki ji je sicer sledila še druga, še večja vojna) ter letom 1648 in začetkom tridesetletne vojne. V reviji smo obravnavali nekatere za protestantizem na Slovenskem pomembne nasledke vojne 1914-1918, drugo smo le omenili in posredno napovedali njeno kasnejšo obravnavo. Tridesetletna vojna gotovo kliče po posebni obravnavi ali vsaj obeleženju $\mathrm{v}$ »reviji za vprašanja protestantizma«: $\mathrm{v}$ nasprotju $\mathrm{z}$ velikima vojnama 2o. stoletja naj bi pri njej namreč šlo za največjo in zadnjo versko vojno na evropskih tleh, $v$ katero naj bi bili prav protestanti še posebej vpleteni, saj naj bi šlo za spopad med katolištvom in protestantizmom. Vojni 2o. stoletja naj bi bili, nasprotno, vojni, v katerih so bili verske spodbude, sredstva in cilji povsem obrobni (čeprav so tudi bili navzoči); še več, v njunih razsežnostih in strahotah vidijo nekateri dokaz, kam je Evropo pripeljala razsvetljenska in brezbožna (ali pa "poganska«) usmeritev, ki se je odrekla krščanski veri in Bogu; usmeritev, ki je v prvi plan postavila materialni napredek in brezobziren boj za materialne interese zemeljskih skupnosti. Seveda je ob takem pogledu (in proti njemu) treba spomniti, da se je tudi v vojnah 2o. stoletja bojevalo, ubijalo in umiralo v imenu boja za nove bogove Naroda/Nacije, za "novo sveto «Naroda in da se je - bolj ali manj (ne)iskreno - tudi bogove naroda (Očetnjave, Matere domovine, Rodu in Rase) povezovalo z edinim/zadnjim krščanskim Bogom. Ta je bil že v Veliki vojni 1914-1918 klican, naj »reši angle- 
škega kralja«, ali nasprotno, »kaznuje Anglijo«, God save the King, Gott strafe England. Ni treba spominjati na poslanstvo, ki naj bi ga v drugi svetovni vojni Božja Previdnost namenila pravi naciji/rasi, da očisti svet Judov in brezbožnih ter odmeri manjvrednim ljudem in ljudstvom mesto, ki jim gre.

Seveda je nujno - in mogoče - tudi v spopadih tridesetletne vojne uvideti in pokazati težo materialnih, dinastičnih, geopolitičnih, ekonomskih interesov, včasih tudi prizadevanja po golem preživetju. Toda dejstvo ostaja, da je bila ta vojna bistveno bolj kot vojni 2o. stoletja spodbujana in vodena tudi s (krščanskimi) verskimi motivi in cilji, da je bila pri mnogih - ne vedno in ne pri vseh - videna in doživljana kot (znotrajkrščanska) verska vojna; da se je v njej odhajalo v boj s klici/gesli "Jezus, Marija« na eni strani in $\mathrm{z}$ »Bog je $\mathrm{z}$ nami« na drugi strani ter da je bil (tudi zato) mir leta 1648 sklenjen »v imenu Svete trojice«. Pa čeprav je bil Sveti sedež dejansko izključen iz mirovnih pogajanj in čeprav naj bi katoliški španski vojaki že leta 1643 pri Rocroyu šli v enega odločilnih spopadov v tej vojni - ki so ga izgubili - z vzkliki "Živela Španija«, verjetno tudi zato, ker jim je nasproti stala vojska prav tako katoliškega francoskega kralja ... Kakorkoli, s tem so napovedovali duha velikih vojn 20. stoletja.

Ob tem spominjanju in opominjanju na podobnosti in razlike med skorajda »brezbožnimi« imperialističnimi/nacionalističnimi vojnami 20. stoletja ter največjo evropsko »versko vojno « 16. stoletja se ne bi spuščali v licitacije, katere in zakaj so bile absolutno ali relativno hujše: vojni 2o. stoletja $z$ desetinami milijonov žrtev in do tal razrušenimi mesti ali tridesetletna vojna s svojimi krutostmi in smrtjo petine ali celo tretjine in več prebivalstva na najbolj izpostavljenih področjih Nemškega cesarstva.

Ob tridesetletni vojni bi se ustavili pri dveh vprašanjih, ki sta relevantni in aktualni tudi ob spremljanju in doživljanju spopadov 21. stoletja.

Prvo je vprašanje o poročanju in predstavljanju vojnih spopadov. Ko danes beremo ohranjena poročila iz te vojne in/ali njene kasnejše predstavitve, seveda naletimo tudi na laži in izmišljotine, na fake news, kot bi rekli danes. Toda že takrat lahko opazimo, da glavni problem (in 
glavno sredstvo propagandnih in versko-ideoloških spopadov) niso bile neresnice, izmišljotine in laži o dogajanju. Take neresnice se s pričevanji, z dokumenti in argumenti slej ali prej ovržejo. Glavni problemi so enostransko in pristransko selekcioniranje resnic, selekcija in manipulacija »faktično resničnih"vesti, njihovo izbiranje ali izpuščanje, osvetljevanje ali zamračevanje dogajanja, relativizacija in abstrahiranje ali konkretizacija in potenciranje pomena posameznih dogodkov ali vidikov. Spremljanje sodobnega enostranskega in pristranskega poročanja o sodobnem vojnem dogajanju (na primer v Siriji) nas naredi še toliko pozornejše na problem poročanja o podobnih dogajanjih v 3o-letni vojni. Pa tudi v drugi smeri: pogled v raznolikost poročanja, predstavljanja in interpretacij nekega oddaljenega in zaradi časovne oddaljenosti čustveno in interesno za nas manj obremenjenega dogajanja nas lahko naredi senzibilnejše in previdnejše pri sprejemanju ponujanih dejstev in razlag o sodobnosti in manj oddaljeni preteklosti.

Vzemimo za primer zgodovinarsko predstavitev zavzetja in uničenja Magdeburga po katoliško-cesarskih četah leta 1631. V krajšem knjižnem prikazu tridesetletne vojne, ki ga imamo tudi v slovenskem prevodu (Stephen J. Lee, Tridesetletna vojna, Ljubljana 1995) lahko preberemo lapidarno poročilo, da so »Tillyjeve čete [Katoliške lige] osvojile, oropale in uničile mesto Magdeburg« in da sta šele po tem protestantski Saška in Brandenburg podprli Švedsko v borbi proti katoliškemu habsburškemu cesarju. Nevtralno poročilo ne da videti prav tistih dejstev in vidikov dogajanja, zaradi katerih je uničenje Magdeburga tako odmevalo in dalo spodbudo za (ponovno) protikatoliško in proticesarsko mobilizacijo v Nemčiji in širše v Evropi. V obsežnejši zgodovini angleške avtorice C. V. Wedgwood (The Thirty Years War, 1938, nemški prevod dopolnjene izdaje 1967, pri sicer katoliški založbi List) lahko preberemo, kaj je pomenilo to »uničenje mesta«: od 30.000 prebivalcev jih je ostalo pri življenju le okrog 5.0oo, največ žensk, ki so jih zmage (in množično tudi dobesedno) pijani vojaki spravili »na varno« v svoje tabore, danes bi rekli kot »spolne sužnje«; ostali so bili pobiti ali so umrli v požarih. Avtorica se celo loti razprave, ali so bili požari, ki so uničili mesto, podtaknjeni, morda celo s strani branilcev mesta samih. Le nekaj sto prebivalcev je našlo za- 
točišče v mestnem samostanu in katedrali, tudi 80 otrok, od katerih jih je preživelo le 15 . Po petih dneh uničevanja je Tilly ukazal vojaško parado, ki se je končala s svečanim Te Deum v ponovno posvečeni mestni katedrali, kjer je oznanil, da mesto odslej ni več Magdeburg, ampak Marienburg, Marijina trdnjava. Hkrati pa si zgodovinarka ne more kaj, da ne bi poskušala poveljnikov Tillyja in Pappenheima nekako izvzeti iz krutega obračuna: poroča, kako je Tilly rešil dojenčka iz rok mrtve matere, kako je pozval priorja samostana, naj ženske in otroke spravlja na varno $\mathrm{v}$ katedralo in samostan, poslal je duhovnike, da bi prepričevali vojake, naj zajete ženske ali poročijo ali jih osvobodijo za ustrezno odkupnino: svoje žene da lahko odkupijo tudi njihovi preživeli možje ...

Posamezni viri, posamezni opisi posameznih dejanj/dejstev pa njihove različne sestavljenke $\mathrm{v}$ tako ali drugačno podobo dogajanja lahko celo pri tako drastično očitnem zločinskem početju različno učinkujejo: kot izraz ali sredstvo ogorčenja ali, nasprotno, kot iskanje opravičevanja ali vsaj relativiziranja in ublaževanja. Vsekakor je v času vojne same - ne glede na kasneje ustvarjene podobe - magdeburški pokol navajal švedske vojake, da so z izrazom »magdeburški pardon « spodbujali/opravičevali tudi svoje brezobzirno obračunavanje s premaganimi nasprotniki.

Obravnava magdeburškega pokola je zgovoren »oddaljen« primer, kako se lahko zgodovinska dejstva uporabljajo tako za mobilizacijo kot za nevtralizacijo njenih učinkov na nasprotni strani. Ko/če se sčasoma nasprotne strani pomirijo (ali zato, da bi se pomirile), ker nekdanje delitve niso več relevantne in aktualne, se uveljavlja praksa, da se o takih dogodkih ne piše več; če pa že, v posplošenem in nevtralnem, čustveno neobremenjenem jeziku. Ve se, da stalno, ritualno izpostavljanje zločinov ene strani kliče po enakem prizadevanju na drugi strani - rezultanta enega in drugega prizadevanja največkrat ni uravnotežena "polnost Resnice", ampak ohranjanje ali celo stopnjevanje nekdanjih delitev in sovraštva. "Ne bomo pozabili, ne smemo pozabiti« - vse do zahtevanega dokončnega/»poštenega« obračuna in poračuna $\mathrm{v}$ imenu Resnice, Pravice in Sprave. Kaj kdaj prevlada, je odvisno od spreminjajočega se konteksta medsebojnih odnosov ljudi, ki so deležni takih nagovorov. Poseben primer in problem je praksa iskanja in razglašanja 
svetnikov-mučencev $\mathrm{v}$ Katoliški cerkvi (seveda tudi v pravoslavju in isla$\mathrm{mu}$ ). Celo če se pri izboru tistih, ki naj bi bili deležni časti oltarja, danes še tako pazi, da bi je bili deležni le tisti, ki so svetniško umrli res le za vero in zaradi vere - če so subjektivno ali objektivno pripadali eni od strani v spopadih in se identificirali z njo, njihova posvetitev, njihova sakralizacija neizogibno navaja na stalno demonizacijo druge strani (ki je zakrivila njihovo mučeniško smrt). Stare in tudi novejše razglasitve katoliških svetnikov iz časa tridesetletne letne vojne (na primer Jana Sarkanderja iz Moravske po Janezu Pavlu II.) so zgovorni primeri neizogibne dvoreznosti razglašanja svetnikov iz časov spopadov, če se sami nad te spopade niso bili sposobni dvigniti, ampak so v njih tako ali drugače sodelovali, ne da bi zavračali in obsojali nasilje na obeh straneh, tudi in zlasti na »svoji«. Kot je ob priliki rekel pokojni nemški škof Josef Homeyer, predsednik Komisije Škofovskih konferenc Evropske unije, se k miru, pomiritvi, spravi in sožitju prispeva le, če se na oltarjih spominja tudi žrtve druge strani, če se ohranja spomin na žrtve, ki smo jih »mi« povzročili. Utopija? In prav zato nujnost. Zdi se, da se tega zaveda tudi sedanji papež Frančišek: na to kaže njegova zadržanost do razglasitve Alojzija Stepinca za svetnika, dokler se o njem ne izrečejo tudi predstavniki Srbske pravoslavne cerkve.

V ozadju pisanja o tridesetletni vojni kot (tudi) verski vojni je danes znova aktualno vprašanje o religiji in nasilju. Še posebej v novejšem času je povezano s tezo, da so prav monoteistične religije tiste, ki v imenu Deus vult, "Bog to hoče«, posredno ali neposredno prispevajo k nasilju in vojni: če hoče Bog, če gre za Božjo čast, potem so dovoljena ali celo zapovedana vsa sredstva, tudi radikalna. Ko gre za Boga in njegovo Resnico, ni mesta za človeške kompromise in izogibanja. Če je krščansko, da človek celo "nastavi še drugo lice«, namesto da se brani ali celo maščuje, potem za kaj takega ni mesta, če gre za sramotenje Boga, za Božjo čast.

Če kaj, je tridesetletna vojna pokazala, da je bila religija (kot osebna vera, kot cerkvena ustanova, kot legitimacija oblasti) vključena v vojno in nasilje: kot spodbujevalec in ojačevalec in/ali kot zavora in odvračevalec. Kot kaj, kdaj in kako, je bilo odvisno od spleta sil in interesov, s 
katerimi se je povezovala ali jim nasprotovala. V različnih obdobjih in okoljih tridesetletne vojne so bile v igri tako rekoč vse možnosti in zmožnosti. Tudi za to je zgovoren magdeburški primer.

$\mathrm{Z}$ distance in njej primerne ležernosti lahko po poznanih opisovanjih in raziskovanjih izrečemo presojo, da je krščanska religija s svojimi notranjimi delitvami in zunanjimi povezavami k vojni in nasilju prispevala svoj delež, da pa pri tem ni bila dominantna. Lahko rečemo, da so bili tako za spopade kot za njihovo začasno in končno prenehanje močnejši drugi razlogi in spodbude. Prav tako bi tudi v tej "zadnji evropski verski vojni« našli primere in dokaze, da je mogoče $z$ vero nasprotovati vojni in nasilju, pa čeprav to še ni bil čas, ki bi nasproti pozivanju k boju za Boga in Božjo čast že uveljavil prepričanje, da naj »Z žalitvijo bogov opravijo bogovi sami« (kot naj bi Voltaire povzel stari rimski napotek) in da krščanskega Boga gotovo ni tam, kjer se ljudje bojujejo zanj (Barth). Kot vemo iz zgodovine, se je to prepričanje uveljavilo šele kasneje, toda le do neke mere, in nobenega zgodovinskega zagotovila ni, da ne bo spet (vsaj začasno) prevladalo nasprotno.

Že na prvi pogled so v tej številki obdelane tri središčne teme: $z g o$ dovinski prikaz in obravnava tridesetletne letne vojne, shajanje in razhajanje humanističnih in reformacijskih nazorov in spodbud tudi v slovenskem prostoru ter nenazadnje spet Trubar in njegovi dosežki.

Razprave, študije te številke začenjajo $\mathrm{z}$ obsežnim in slikovitim prikazom tridesetletne vojne Igorja Grdine, s pronicljivimi opažanji in poudarkom na njenem prvem obdobju in dogajanju v srednjeevropskem prostoru. Jonatan Vinkler tudi na osnovi svojega dela pri izdajanju Trubarjevih Zbranih del razpravlja o Trubarjevi prevajalski paradigmi, ki je običajno (pre)hitro in parcialno branje ne omogoča uvideti. Cvetka $\mathrm{H}$. Toth je v svoji osvetlitvi Nietzschejeve antropološke in etične misli posebej pozorna na njegove navezave in vzporednice $\mathrm{z}$ mislijo Martina Luthra.

V Študijskih večerih Božidar Debenjak obravnava in dokumentira pojmovanje spola, spolne razlike in spolnosti v Bibliji. Marko Marinčič s svojim prispevkom nadaljuje raziskovanje delovanja Petra Pavla Vergerija v naši reviji (prisotno v člankih Silvana Cavazze, Tomaža Jurce in posredno Fulvia Tomizze v prejšnjih številkah): pri vpogledu v Vergerijeva la- 
tinska besedila se posebej posveti humanističnim in reformacijskim izhodiščem in pobudam Vergerijeve "jezikovne politike" nasproti širšemu južnoslovanskemu prostoru. Mihael Glavan objavlja nova spoznanja o življenja in delu Janža Znojilška (1568-1659) iz ugledne ljubljanske protestantske rodbine, katere mnogi člani so se v času protireformacije izselili v nemške dežele. Nekateri od njih so se uveljavili v švedskem okolju in zapustili spomin na svoje poreklo tudi potomcem, med katerimi je bil pomembni švedski pesnik Carl Snoilsky, ki je v začetku 2o. stoletja navezal stike $\mathrm{z}$ Antonom Aškercem. Usoda in življenjske poti izseljencev v času tridesetletne letne vojne in po njej še čakajo na raziskovanje in predstavitev tudi v naši reviji.

V rubriki Bilo je povedano nadaljujemo s prikazom razmerja med humanizmom in reformacijo na Slovenskem (glej članek Štefana Barbariča $\mathrm{v}$ št. 28), tokrat $\mathrm{z}$ izborom ugotovitev in presoj lani preminulega klasičnega filologa Primoža Simonitija.

$\mathrm{V}$ Razgledih in vpogledih zakonca Ilić, zaslužna raziskovalca južnoslovanskega, tudi slovenskega protestantizma nakazujeta raznoliko mesto in vlogo protestantskih verskih skupnosti $\mathrm{v}$ raznolikosti naslednic nekdanje Jugoslavije.

Kot Prevod smo tudi zaradi letošnje 10o-letnice ljubljanske univerze in oživitve razprav o sedanjem osnovnošolskem izobraževanju tokrat ponudili izbor humanističnih in reformacijskih misli Martina Luthra in Philipha Melanchthtona o pomenu izobraževanja in šole, posebej o nalogah in poslanstvu učitelja, nenazadnje univerzitetnega.

V Kroniki smo obeležili 25-letnico ustanovitve Slovenskega protestantskega društva Primož Trubar, ustanovljenega 14. oktobra 1994, in sicer s ponatisom zapisa Marka Kerševana o(b) tem v Sobotni prilogi Dela 29. oktobra 1994. Zabeležili smo tudi položitev spominske plošče ob 50o-letnici reformacije v tlak pred sedanjo evangeličansko cerkvijo v Ljubljani.

Član uredniškega odbora revije od leta 2007, zdaj upokojeni zaslužni profesor Teološke fakultete Univerze v Ljubljani dr. Ciril Sorč, nam je sporočil, da ne more več aktivno sodelovati pri delu uredništva. Spoštovanemu sodelavcu se za njegovo sodelovanje iskreno zahvalju- 
jemo; bilo nam je v čast in oporo, še posebej v najtežjih prvih letih izhajanja. Izvršni odbor društva je na predlog uredništva junija 2019 za novo članico imenoval dr. Faniko Krajnc-Vrečko, znanstveno sodelavko in vodjo knjižnice Teološke fakultete Univerze v Ljubljani (oddelek v Mariboru), že do sedaj sodelavko revije in sodelavko pri izdajanju Zbranih del Primoža Trubarja.

Marko Kerševan 